\title{
Morfologia de esporos de pteridófitas do Parque Estadual das Fontes do Ipiranga (São Paulo, Brasil) \\ Famílias: 6-Dicksoniaceae, 12-Lophosoriaceae, 14-Ophioglossaceae
}

\author{
Carolina Brandão Coelho ${ }^{1}$ e Luciano Mauricio Esteves ${ }^{1,2}$
}

Recebido: 03.04.2007; aceito: 04.09.2008

ABSTRACT - (Morphology of spores of pteridophyte from the "Parque Estadual das Fontes do Ipiranga" (São Paulo, Brazil) families: 6-Dicksoniaceae, 12-Lophosoriaceae, 14-Ophioglossaceae). Spores of pteridophyte species of the families Dicksoniaceae, Lophosoriaceae and Ophioglossaceae from the "Parque Estadual das Fontes do Ipiranga" were studied. The families are represented in the area by three species: Dicksonia sellowiana, Lophosoria quadripinnata and Ophioglossum palmatum. Descriptions, illustrations and observations are presented.

Key words: Dicksonia, Lophosoria, Ophioglossum, spores

RESUMO - (Morfologia de esporos de pteridófitas do Parque Estadual das Fontes do Ipiranga (São Paulo, Brasil) famílias: 6-Dicksoniaceae, 12-Lophosoriaceae, 14-Ophioglossaceae). Foram estudados os esporos de pteridófitas pertencentes às famílias Dicksoniaceae, Lophosoriaceae e Ophioglossaceae do Parque Estadual das Fontes do Ipiranga. Estas famílias são representadas na área por três espécies, respectivamente: Dicksonia sellowiana, Lophosoria quadripinnata e Ophioglossum palmatum. Para todos os táxons estudados são apresentadas descrições, ilustrações e observações sobre as espécies.

Palavras-chave: Dicksonia, esporos, Lophosoria, Ophioglossum

\section{Introdução}

A família Dicksoniaceae possui seis gêneros e cerca de 45 espécies (Kramer 1990), com distribuição pantropical (Pérez-Garcia 1995). Na área do Parque Estadual das Fontes do Ipiranga (PEFI), a família é representada apenas pela espécie Dicksonia sellowiana Hook. facilmente reconhecida pelo hábito arbóreo, crescendo em locais sombreados e úmidos (Fernandes 2000). É uma espécie considerada como ameaçada de extinção devido à intensa exploração comercial para extração do caule arborescente, utilizado para fabricação do xaxim (Prado 2004b) e é a única espécie de pteridófita incluída na lista oficial de espécies ameaçadas de extinção no Brasil (IBAMA 1992).

A família Lophosoriaceae é exclusivamente neotropical e, de acordo com dados moleculares recentes, este grupo foi incorporado à família Dicksoniaceae (Smith et al. 2006), classificação não adotada aqui, mantendo-se aquela adotada por Prado (2004a) no planejamento da série "Criptógamos do Parque Estadual das Fontes do Ipiranga, São Paulo, SP. Pteridophyta". Esta família é representada na área do PEFI apenas por Lophosoria quadripinnata (J.F. Gmel.) C. Chr. var. quadripinnata, facilmente reconhecida pelo hábito cespitoso, com frondes grandes (2,5 m de comprimento) e pecíolo na base com muitos tricomas, crescendo no interior e margem de matas, em locais sombreados.

A família Ophioglossaceae apresenta plantas terrestres ou epífitas de distribuição cosmopolita (Prado 2004c). Apesar de possuir quatro gêneros e cerca de 80 espécies (Smith et al. 2006), são de ocorrência rara e anual. Na área do PEFI somente há coletas de Ophioglossum palmatum L.. Hoehne et al. (1941) registraram a presença de O. ellipticum (=O. nudicaule L.), porém esta não foi coletada recentemente na área e o material não foi localizado nos herbários SP e SPF (Prado 2004c).

Este trabalho dá continuidade aos estudos morfológicos em esporos de pteridófitas do PEFI (Esteves \& Coelho 2007) e dá suporte para a pesquisa sobre precipitação esporo-polínica e análise palinológica de sedimentos na área.

\section{Material e métodos}

O planejamento do estudo da presente flora polínica foi baseado em Melhem et al. (1984). Os dados referentes à localização e caracterização do Parque

1. Instituto de Botânica, Caixa Postal 3005, 01061-970 São Paulo, SP, Brasil

2. Autor para correspondência: luciano.esteves@uol.com.br 
Estadual das Fontes do Ipiranga (PEFI) encontramse nos trabalhos de Melhem et al. $(1981,1984)$. A chave para identificação das espécies das famílias Dicksoniaceae, Lophosoriaceae e Ophioglossaceae no PEFI foi publicada em Prado (2004a).

Os esporos coletados foram obtidos de material herborizado, depositado no Herbário Científico do Estado "Maria Eneyda P. Kauffmann Fidalgo" (SP). Quando os espécimes apresentavam-se inférteis, ou com quantidade insuficiente de esporos, optou-se por coletas a partir de exsicatas provenientes de outras localidades.

Os esporos foram preparados segundo a técnica de acetólise (Erdtman 1960). As ilustrações foram obtidas em microscopia óptica de esporos acetolisados e fotografados digitalmente, utilizandose fotomicroscópio Olympus BX 50, acoplado a uma câmara de vídeo e microcomputador (PC) e o programa Pro-Plus versão 3 para Windows. Foram medidos os diâmetros equatorial $(\mathrm{E})$ e polar $(\mathrm{P})$, o comprimento da lesão (L) e a margem da lesão (ML), determinando-se a média, o intervalo de confiança a $95 \%$ e o coeficiente de variabilidade da amostra. A nomenclatura utilizada nas descrições dos esporos é baseada em Lellinger (2002). As lâminas preparadas encontram-se depositadas na Palinoteca da Seção de Dicotiledôneas, Instituto de Botânica.

\section{Resultados e Discussão}

\section{Família Dicksoniaceae}

\section{Dicksonia L'Hér.}

\section{Dicksonia sellowiana Hook.}

Figuras 1-6

Forma: trilete, tetraédrico. Lobos proeminentes e com uma grande depressão entre os braços da lesão.

Lesão: braço da lesão aproximadamente $3 / 4$ do raio

Estrutura: exosporo granulado apresentando pequenas perfurações, formado de duas camadas, a mais externa aproximadamente três vezes mais espessa do que a interna. Perisporo formado por duas camadas, a interna fina, transparente e facilmente fragmentada pela acetólise e uma mais externa formada por deposição de material granulado.

Medidas ( $\mu \mathrm{m})$ : C. Spannagel s.n. (SP22016): P $=47,6 \pm 0,5 ; \mathrm{E}=64,5 \pm 0,6 ; \mathrm{L}=24,7 \pm 0,7 ; \mathrm{ML}=$ $4,2 \pm 0,2$.
H. Luederwaldt s.n.(SP22020): $\mathrm{P}=50,6 \pm 0,8 ; \mathrm{E}$ $=64,2 \pm 0,8 ; \mathrm{L}=22,5 \pm 1,1 ; \mathrm{ML}=3,8 \pm 0,3$.

Observações: os materiais $H$. Luederwaldt s.n. (SP22017) e J. Prado \& G.B. Silva 1412, citados por Prado (2004b), não foram estudados por apresentarem esporos em quantidade insuficiente para a análise. Foram estudados os materiais C. Spannagel s.n. (SP22016) e H. Luederwaldt s.n. (SP22020), provenientes de outra localidade.

Material examinado: BRASIL. Santa Catarina: Lages, s.d., C. Spannagel s.n. (SP22016) e BRASIL. São Paulo: Ipiranga, cultivada no Horto Botânico de São Bernardo do Campo, s.d., H. Luederwaldt s.n. (SP22020).

Família Lophosoriaceae

Lophosoria C. Presl

\section{Lophosoria quadripinnata (J.F. Gmel.) C. Chr. var. quadripinnata}

Figuras 7-15

Forma: trilete, com pólo proximal plano e pólo distal hemisférico, e uma borda equatorial proeminente.

Lesão: braço da lesão aproximadamente $2 / 3$ do raio.

Estrutura: exosporo formado por duas camadas, a externa ornamentada por tubérculos irregulares entre os braços da lesão no pólo proximal, e perfurações bem definidas no pólo distal. Perisporo fino, microrreticulado, eventualmente com granulações facilmente removidas durante a acetólise.

Medidas $(\mu \mathrm{m}): \mathrm{P}=53,7 \pm 0,9 ; \mathrm{E}=74,7 \pm 1,1 ; \mathrm{L}$ $=25,8 \pm 0,4 ; \mathrm{ML}=2,8 \pm 0,1$.

Observações: o material J. Prado et al. 1564 , citado por Prado (2006), não foi estudado por apresentar esporos em quantidade insuficiente para a análise.

Material examinado: 20-XII-2005, J. Prado 1611 (SP).

\section{Família Ophioglossaceae}

\section{Ophioglossum L.}

\section{Ophioglossum palmatum $\mathrm{L}$.}

Figuras 16-19 

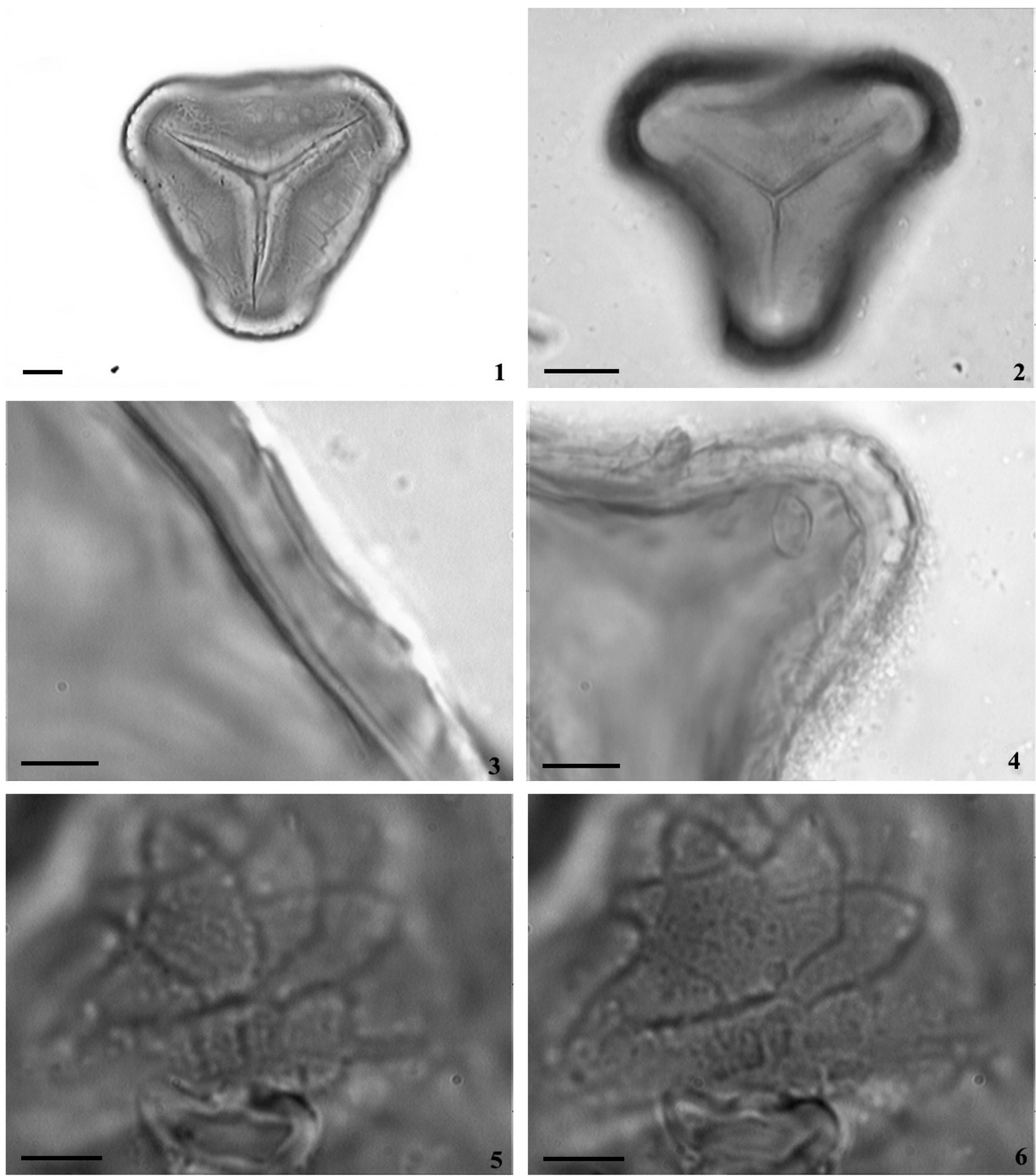

Figuras 1-6. Fotomicrografias de esporos de Dicksonia sellowiana Hook. 1. Vista polar proximal. 2. Vista polar proximal, detalhando lobos proeminentes e depressão entre os braços da lesão. 3. Corte óptico da parede, exosporo (E) de duas camadas e perisporo (P) fino. 4. Corte óptico da esporoderme, perisporo (P) fino e transparente formado por deposição de material granulado. 5-6. Análise de L.O., foco alto e baixo, respectivamente, presença de grânulos e pequenas perfurações irregulares. Barras de escala: $3,5-6=5 \mu \mathrm{m} ; 1,4=10$ $\mu \mathrm{m} ; 2=15 \mu \mathrm{m}$. 

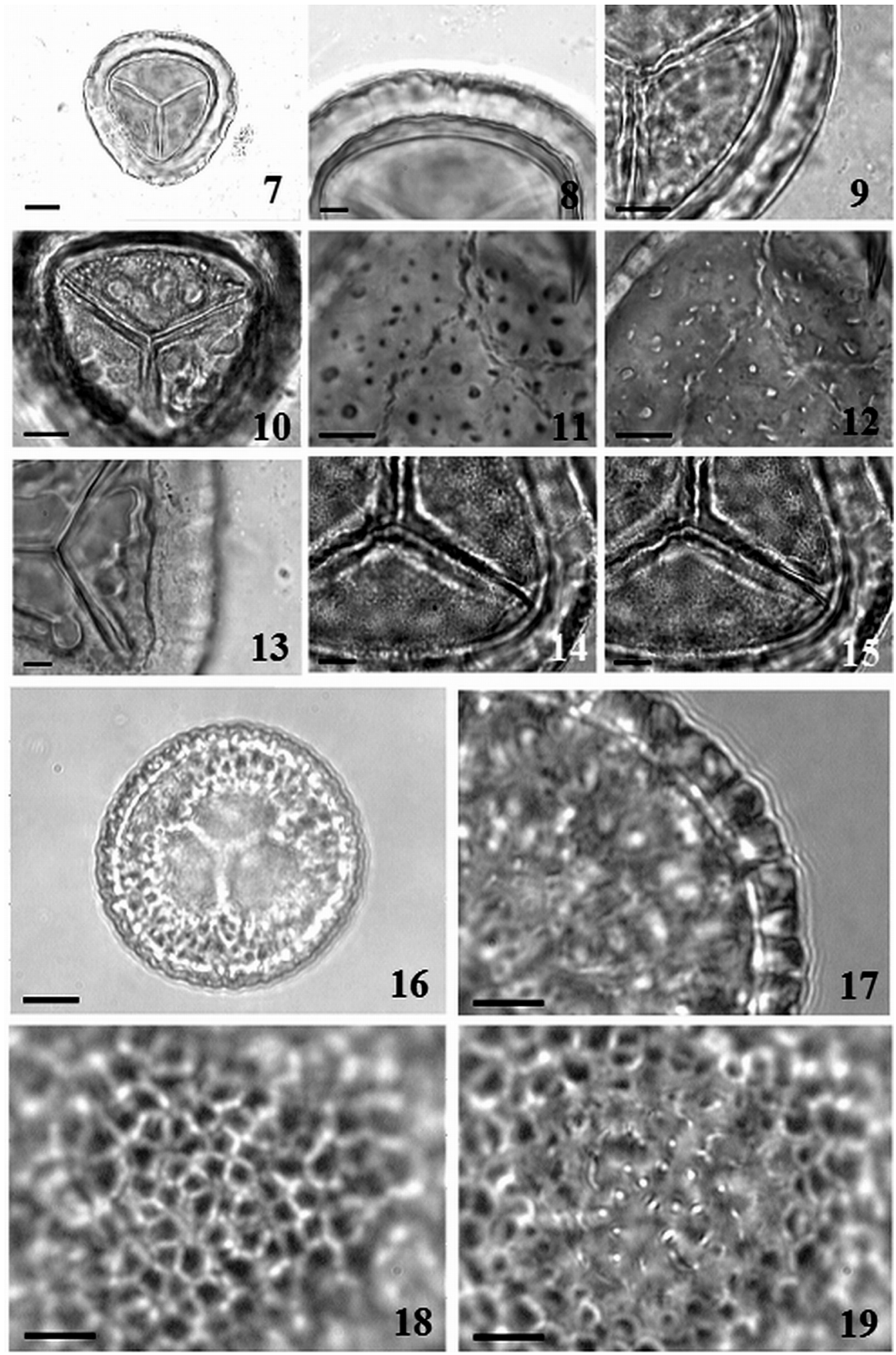

Figuras 7-19. Fotomicrografias de esporos dos gêneros Lophosoria (Lophosoriaceae) e Ophioglossum (Ophioglossaceae). 7-15. Lophosoria quadripinnata (J.F. Gmel.) C. Chr. var. quadripinnata. 7. Vista polar proximal. 8. Corte óptico da parede. 9. Corte óptico pelo exosporo. 10. Vista polar proximal, detalhe dos tubérculos entre os braços da lesão. 11-12. Análise de L.O. foco alto e baixo respectivamente da vista polar distal. 13. Corte óptico, perisporo granulado. 14-15. Análise de L.O., foco alto e baixo respectivamente, perisporo microrreticulado. 16-19. Ophioglossum palmatum (L.). 16. Vista polar proximal. 17. Corte óptico da parede. 18-19. Análise de L.O., foco alto e baixo, respectivamente, exosporo reticulado. Barras de escala: 8, 13-15, 17-19=5 $\mu \mathrm{m} ; 9-12,16=10 \mu \mathrm{m} ; 7=15 \mu \mathrm{m}$. 
Forma: trilete, globosos.

Lesão: braço da lesão aproximadamente $2 / 3$ do raio.

Estrutura: exosporo formado por três camadas de difícil visualização, a mais externa reticulada. Perisporo fino, psilado, contornando o exosporo, e é facilmente removido pela acetólise.

Medidas $(\mu \mathrm{m}): \mathrm{P}=53,2 \pm 0,8 ; \mathrm{E}=71,9 \pm 0,6 ; \mathrm{L}$ $=23,9 \pm 0,3 ; \mathrm{ML}=6,3 \pm 0,1$.

Material examinado: 27-VI-1933, F.C. Hoehne s.n. (SP30805).

\section{Agradecimentos}

Os autores agradecem ao Dr. Jefferson Prado pela identificação do material.

\section{Literatura citada}

Erdtman, G. 1960. The acetolysis method. A revised description. Svensk Botanisk Tidskrift 39: 561-564.

Esteves, L.M. \& Coelho, C.B. 2007. Morfologia de esporos de pteridófitas do Parque Estadual das Fontes do Ipiranga (São Paulo, Brasil). Família: 5-Dennstaedtiaceae. Hoehnea 34: 245-252.

Fernandes, I. 2000. Taxonomia dos representantes de Dicksoniaceae no Brasil. Pesquisas, Botânica 50: 5-26.

Hoehne, F.C., Kuhlmann, M. \& Handro, O. 1941. O Jardim Botânico de São Paulo. Secretaria da Agricultura, Indústria e Comércio, Departamento de Botânica do Estado, São Paulo.

IBAMA. 1992. Portaria $\mathrm{n}^{\circ}$ 37-N, de 3 de abril de 1992: Lista Oficial de Flora Ameaçada de Extinção. IBAMA, Ministério do Meio Ambiente. http://www.ibama.gov. br/flora/extincao.htm (acesso em 25.07.2008)

Kramer, K.U. 1990. Dicksoniaceae. In: K.U. Kramer \& P.S. Green (eds.). Pteridophytes and Gymnosperms. In:
K. Kubitzki (ed.). The families and genera of vascular plants. Springer Verlag, Berlin, v. 1, pp. 94-99.

Lellinger, D.B. 2002. A modern multilingual glossary for Taxonomic Pteridology. Pteridologia n.3. American Fern Society, Washington.

Melhem, T.S., Giulietti, M., Forero, E., Barroso, G.M., Silvestre, M.S.F., Jung, S.L., Makino, H., Fiuza-deMelo, M.M.R., Chiea, S.C., Wanderley, M.G.L., Kirizawa, M. \& Muniz, C. 1981. Planejamento para a elaboração da "Flora Fanerogâmica da Reserva do Parque Estadual das Fontes do Ipiranga (São Paulo, Brasil)". Hoehnea 9: 63-74.

Melhem, T.S., Makino, H., Silvestre, M.S.F., Cruz, M.A.V. \& Jung-Mendaçolli, S. 1984. Planejamento para a elaboração da "Flora Polínica da Reserva do Parque Estadual das Fontes do Ipiranga (São Paulo, Brasil)". Hoehnea 11: 1-7.

Pérez-Garcia, B. 1995. Dicksoniaceae. In: R.C. Moran \& R. Riba (eds.). Psilotaceae a Salviniaceae. In: G. Davidse, M. Sousa \& S. Knapp (eds.). Flora Mesoamericana. Universidad Nacional Autónoma de México, Ciudad de México, v.1, pp. 86-88.

Prado, J. 2004a. Criptógamos do Parque Estadual das Fontes do Ipiranga, São Paulo, SP. Pteridophyta: chave para as famílias: 2. Blechnaceae. Hoehnea 31: 1-10.

Prado, J. 2004b. Criptógamos do Parque Estadual das Fontes do Ipiranga, São Paulo, SP. Pteridophyta: 6. Dicksoniaceae. Hoehnea 31: 239-242.

Prado, J. 2004c. Criptógamos do Parque Estadual das Fontes do Ipiranga, São Paulo, SP. Pteridophyta: 14. Ophioglossaceae. Hoehnea 31: 171-174.

Prado, J. 2006. Criptógamos do Parque Estadual das Fontes do Ipiranga, São Paulo, SP. Pteridophyta: 12. Lophosoriaceae. Hoehnea 33: 123-126.

Smith, A.R., Pryer, K.M., Schuettpelz, E., Korall, P., Schneider, H. \& Wolf, P.G. 2006. A classification for extant ferns. Taxon 55: 705-731. 